\title{
Habitat: The Basic Point of Ecological Aesthetics
}

\author{
Zhou Yanxian \\ Foreign Language College of Baise University, Biase, Guangxi, 533000, China
}

Keywords: Habitat, Ecological Aesthetics, Dynamic Correlation, Base Point

\begin{abstract}
Ecological aesthetics is a new development form of aesthetics in the new era. It is a kind of ecological (life) philosophy and aesthetics that seeks harmony and unity of man and nature in a whole. It proposes that ecological beauty is the aesthetic essence of the holistic realization of the potential of human and habitat, and emphasizes the basic significance of habitat for the germination, development and promotion of life, ecology and aesthetic ecology. Habitat is the formation of eco-aesthetic system, the starting point of development, and the basis point of perfection. It shows the dynamic correlation between habitat development and eco-aesthetics development. Habitat is the basic logical structure of ecological aesthetics. It produces, develops and achieves beauty, and then forms, develops, enhances the aesthetic ecology and moves toward the aesthetic field of aesthetic structure, thus achieving ecological aesthetics. By virtue of this, "Habitat" goes beyond the notion of ecology and ascends to a philosophical natural "Tao" that produces the life of all things, and has become the source and fundamental category of ecological aesthetic system.
\end{abstract}

\section{Introduction}

The era of ecological civilization is the aesthetic ecological era. The ecological beauty is a kind of common sense and song of life triggered by the connection between man and nature. It is the aesthetic beauty of human existence. [1] At the moment when ecological aesthetics has gradually become a new development of aesthetics, concepts such as habitat, life and ecology have been given new connotation and significance.

The basic point is the foundation and foundation of the development of things. Its basic definition is the center and the focus. The basic point mentioned here refers to the starting point and starting point of ecological aesthetic system. Ecological aesthetics originated in the modern context of China. Chinese ecological aesthetics has formed a modern aesthetics which is different from Western environmental aesthetics and practical aesthetics, life aesthetics, and so on. The fundamental difference is that the fundamentals of these disciplines vary. Western environmental aesthetics, as a form of human aesthetics, takes the environment as the object of aesthetics, and its theme is the appreciation of the primitive environment and man-made environment. Practical aesthetics emphasizes man's rationality and sociality. It holds that the essence of human beings is the power of practice, the essence of man is practice, and the reason why man differs from animal lies in the "practice" of making tools and using tools to transform nature. [2]

\section{Habitat is the Basis for the Formation of Ecological Aesthetics}

The origin significance of habitat for ecological aesthetics is embodied in the relationship between habitat and life, in the meaning of habitat for the spontaneous development of ecological beauty and in the seminal meaning of habitat for the germination of ecological aesthetic system.

\subsection{Habitat is the source of life}

Habitat is the sum of the living space and all the ecological factors in the living being, and is a comprehensive living system that depends on the germination, survival and growth of the living system. 


\subsubsection{Health pregnant students from habitats}

Life aesthetics regards life as the essence of human being, defines life from the condition of human aesthetic activity, and holds that the pursuit of human life and the demand of life are the intrinsic motive force for the development, survival and growth of human's aesthetic consciousness, thus arguing that life is the starting point of aesthetic logic. So, how is life's germinal? Ecological aesthetics holds that people, like all things in nature, are only elements of life in the ecosystem. All life in nature comes from habitats. Professor Yuan Ding-sheng discusses the germination of life from the point of view of learning and the relationship between ecology and life, and emphasizes the position of systematic life from habitat. He pointed out that though ecology and life are mutually causalities, from the angle of occurrence science, the most primitive life is not born of life, but integrated with comprehensive ecological conditions. Integrated ecosystems form habitats in which the most primitive lives are conceived. [5]

\subsubsection{The quality of life is habitat}

The quality of life, such as the quality of life in biological life, the elegance and sentiment of spiritual life, the dignity of social life, or the development path of life, the difference of the quality of life, are derived from the pros and cons of habitat Sexuality, diversity, complexity or variability. In the case of humans, the beginning to the end of life is done in the nurturing habitat, living habitat and growing habitat. From the perspective of habitat, the systematic development of life can not be separated from family habitat, school habitat and social habitat. First of all, individual life provides physical and spiritual conditions for survival and development in the family habitat consisting of basic gender relations, such as food with belly fat and cold clothes, while the family habitat Members take care of each other, care for and care for the emotional needs of life, and become an important spiritual force that supports the existence of life.[6] Second, in the growth and development of individual life, we can not lack the school education habitat. School habitat is to help mankind from ignorance, toward an advanced place of human civilization, education environment, teaching resources, a good style of study is the condition and harmonious relationship between teaching and learning, relationship between teachers and students to promote the improvement of the quality of education, school Habitat for the self-development and quality of life to enhance the foundation laid the necessary conditions. At the same time, the importance of social habitat for people with social attributes is obvious. In the social habitat, all kinds of relations are more complicated, living conditions are more and more abundant, and their ability to develop is more and more mature, and the quality of life is also promoted.

\subsubsection{The evolution of life from habitat}

The relationship between humans and habitats is the result of long-term evolution. On the one hand, humans can adapt to many habitats. For example, a person's life from birth, growth to the end of life is completed in the micro, meso and macro habitat, he is not affected by internal and external habitat at all times, his growth is family habitat, the school habitat and social habitat cross, The process of comprehensive impact. [7]On the other hand, humans can also transform habitats. For example, human beings occupy new habitats according to their own survival needs, taking the example of the Alpine Han nationality living in the remote mountainous areas of ethnic minorities. In order to change their living condition, these mountainous Han nationals lived in poor natural conditions with inconvenient transportation and economic backwardness. In order to change their living condition, they migrated to the foot of the mountain with gentle terrain, fertile soil, and extensive transportation. In the open area, the habitat of a new mountain Han. It's Here are their new living space and various ecological factors that affect their survival and development, including biological and abiotic factors, natural and social conditions and other ecological factors. In adapting to this new habitat, the Alpine Han people may form a new way of life and production which will be affected by the contact of the surrounding languages and cultures, giving birth to a form different from the previous existence and development, thus reflecting the habitat in the national migration and its social development and changes in the impact of the role. In the continuous evolution of the 
relationship between mankind and habitat, habitat provides a place and condition for the hypercycle and evolution of human life, and thus has the quality of the development of the hyper cycle. First of all, the habitat on which human beings grow and develop depends on the cycle of development and change. When human beings have established their own small family and entered a new family habitat, the cycle of the next round of changes in the habitat begins. In this way, human beings, once and for all, begin the cycle of habitats needed for the next new individual life in the family habitat, school habitat and social habitat from the inception, survival, growth and development of one life. This cycle is a kind of super-cycle, with the characteristics of spin-forward.

\subsection{Habitat is the ecological basis}

After the birth of the initial life, with its habitat, environment, background of life, to a circular movement, the number of evolution, evolution, differentiation of various species, the formation of a biological pedigree. After the biological pedigree germinates, different species occupy their own position, they loop back to life, the formation of ecological chain, constitute the biosphere. The different species in the biosphere and each personage form a reciprocal relationship with their habitat, environment and background and constitute innumerable species and ecological communities [8]. They constitute an ecosystem based on ecology, competition and symbiosis, So that the biosphere upgrade has become an ecosystem; outside the biosphere, the biosphere itself has become a larger ecosystem centered on the biosphere, with its habitat environment, environment environment and background environment. In the ecological circle, the life and habitat in the ecosystem live in, show the aesthetic relationship, produce aesthetic activities, the aesthetic ecosystem of the germinal. Life evolved and evolved into a biological pedigree. It formed a biosphere, upgraded itself into an ecological circle, formed an aesthetic ecology, gave birth to the essence of natural beauty field, and developed the boundaries and texture of natural beauty field. All of these can not be separated from the soil effect of habitat.

Professor Yuan, Dingsheng proposed that "ecological beauty is the natural realization of the all-round nature of human and habitat potential." [6] The potential, quality, ecological activities, habitat, environment, background six coupling counterparts, they go hand in hand, reaching the super-cycle monsters, the formation of the essence of beauty. [7] "Beauty is the whole life," the beauty of the essence of view, is the ecological aesthetics of Yuan Yuan's standpoint and starting point. Habitat refers not only to the living space of human beings (or individual living beings), but also to the total of all ecological factors therein, as well as to the ecosystem in which system life depends on germination, survival and growth; not only the ecological environment in the ecological sense. It is also the "Tao" of nature in the philosophical sense. The essence of beauty is formed in the whole process of things. The interaction, mutual influence, mutual conversion and continuous improvement of habitat and environment and background provide the place, relationship and condition for ecological activities, play an indispensable role in the process. Habitat, in the nature of ecologically beautiful hair system occupies an indispensable person. The beauty of the ecosystem, after all, is inseparable from the conditions of the ecosystem, can not do without the fundamental role of habitat.

\subsection{Habitat is a meta-point generated by ecological aesthetics system}

The basic point, but also the starting point, including the formation of the yuan, the fulcrum of development. Yuan point, that is, the starting point, birth point. Habitat is a systematic production of ecological aesthetics of the yuan, ecological aesthetics system is the starting point and breeding point.

\subsubsection{Habitat is the starting point of aesthetic ecology}

Habitat as a biological living space and all the ecological factors in the total, Habitat formed a system of life depends on a complete ecosystem, the ecosystem refers to a certain space in nature, life in this particular living space and all Ecological environment and the environment (natural environment and social environment, which is the sum of ecological factors. This unified whole shows the laws of the universe, ecological laws and aesthetic rules [9]. These laws also reflect the 
cosmology, ecology and ecology of ecological aesthetics.

The aesthetic law is the law of mankind's aesthetic and creation since ancient times, and is the inherent law of human existence and development. Aesthetic potential is a high-level part of the latent energy system of the living body, and is the aesthetic quality and function of the hidden body of the living body. Aesthetic potential is from a spontaneous spontaneous state to a conscious state of consciousness. The aesthetic potential of the living body is developed in the ecological relationship between the living body and its habitat, environment and background. In the habitat, the original living body can be bred, grow and develop. When it begins to have various sensations of understanding and perceiving the world, its aesthetic potential has been developed and esthetic consciousness has been formed. Subsequently, the living body began an aesthetic activity, which continuously enriched the aesthetic experience, enhanced the aesthetic taste and realized the aesthetic freedom. At this time, the aesthetic subject and the object attract each other and attract each other, gather together, blend together and assimilate with each other, forming the best aesthetic phenomenon and the best aesthetic realm, thus creating the aesthetic field. [9] Structured aesthetic field is composed of aesthetic appreciation, criticism, research and creation of the cycle of the formation of aesthetic activity cycle, the ecological aesthetic circle of activities and the ecosystem together, formed the ecological aesthetic field, which developed the aesthetic ecology. Habitat is the condition for the potential development of the aesthetic potential of the living body, the result of the aesthetic choice of the living body, the realization of the aesthetic activity and the aesthetic freedom, and the starting point of the aesthetic ecology[10].

\subsubsection{Habitat is the source of ecological aesthetic system category}

The nature of habitat contains the formation of ecological aesthetics. According to the cosmopolitan view of ecological aesthetics, "lifetime" or "whole life" is the universal nature and characteristics of existence, the basic law of the origin and composition of the world, and the universal law of the birth of living beings and ecosystems. Systematic life originates from habitat. Habitat's life originates from the spinnability of the universe. Spin-life of the universe is a matter-of-fact issue of eco-aesthetics. In the theoretical system of eco-aesthetics of Professor Yuan Dingsheng, habitat is generated in the spin-cycle of the universe and is a combination of the ecological conditions of all natural things, which comes before the primitive life. The most primitive life in hair habitat, this habitat is like the world of all things, the mother of all things, all things in the world to be nurtured, growth and development. Habitat here is no longer the concept of ecology, but a source of philosophical color in the system of ecological aesthetics[11].

\section{Habitat is the Starting Point of the Development of Ecological Aesthetics}

After the development of ecological aesthetics to a certain period, its logical element, namely habitat, can grow and become an organism with dialectical growth. This organism, as a unitary entity, has achieved its own ascent and development as a systematic life, with an integral paradigm, a super-cyclic system and a spin-off system. At the same time, it continues to provide the system for the growth, development and promotion of the system's life Places, relationships and conditions, which provide impetus to the spiral of the biosphere and ecosystem. They are the necessary conditions for the healthy operation of ecosystems and the driving force for the fractal transformation of ecological aesthetics.

\subsection{Habitat is a condition for the healthy operation of ecosystems}

Ecological aesthetics is a science that studies the aesthetic germination, aesthetic survival and aesthetic growth of the whole ecosystem. What it is supposed to construct is the ecosystem that the natural potential of human and the habitat can be realized naturally [10]. Ecological aesthetics holds that the universe is a community of life composed of system life and individual life, and is a complex life system in which various life elements are interdependent and interacting. The common place of existence owned by the life community constitutes a complete ecosystem, namely the habitat; and each living body in a different position in the ecosystem shows different germinal, 
survival and growth because of its niche The laws, characteristics and quality constitute the diversity and heterogeneity of life shown in the ecosystem.

\subsection{Habitat is the driving force of ecological aesthetics fractal}

When quoting the concept of "Habitat" many times and referring to the ideological foundation of ecological aesthetics, Professor Yuan Dingsheng regarded the overall ecological aesthetics as the direct habitat of ecological aesthetics. In its historical neutralization, it reflects a kind of ecological holism, which is a philosophical view that the sum of parts is greater than the whole. When discussing the formation and development of ecological aesthetics, he said that the habitat of ecological aesthetics is aesthetic culture and civilization. In its counterparts with aesthetic culture and civilization, ecological aesthetics has increased the unification of ecology and aesthetics, becoming a Ecological beauty and culture, expanding its own territory; human culture and civilization, the relationship between nature and nature constitute a whole system; as ecological aesthetics depends on hair habitats, ecological aesthetic culture and civilization, through nature, formed a social and natural whole aesthetic field, constitute the aesthetic activities, aesthetic atmosphere and aesthetic paradigm composed of aesthetic ecosystem.

\section{Habitat is the Basis of Ecological Aesthetics}

Natural beauty is the ultimate ideal of ecological aesthetics; beauty is the perfection of ecological aesthetics. Habitat, first of all, is the foundation of the formation and development of life and aesthetic ecology. It is the starting point of the formation and development of ecological aesthetics. In the stage of ascension of life, aesthetic and ecological aesthetics, habitat continues to exert its fundamental significance and becomes the ultimate ideal of ecological aesthetics - the carrier of natural beauty and beauty, provides the foundation and base for the realization of eco-aesthetics.

\subsection{Habitat is the carrier of natural beauty}

Whether it is about the source of life or the issue of aesthetic ecology, the status and role of habitat can not be underestimated. The original life from the habitat is a kind of beauty and a life of beauty. When the primitive life is in a single cell inoculation, it has not formed a certain psychological structure and has no aesthetic ability and consciousness, so it has not formed aesthetic conditions. When primitive cells of life are conceived in habitats, grown into living beings, and living beings are in constant development, sensations of the world are formed through visual, auditory, olfactory and tactile sensations, and aesthetic needs and possibilities begin to emerge. So also produced aesthetic activities. In this sense, the habitat not only produces and develops life, but also enhances life. It makes life have aesthetic needs, develop aesthetic functions and aesthetic possibilities, thus solving the basic problems of ecological aesthetics[12].

\subsection{Habitat is the foundation of ecological aesthetics}

Ecological aesthetics toward natural aesthetics, to achieve its own perfection - the United States and health, inseparable from the development and improvement of habitat; nature beauty field can not do without the birth of the basic role of the ecological aesthetic habitat.

\subsubsection{Habitat is the improvement of the environment}

The development and improvement of habitat is the result of mutual conversion and interaction with each other in the environment. Habitat, is the reality of the ecological environment. Professor Yuan Dingsheng proposed: "If we say that habitat is the source of the element of life and the ecological environment is the home of life," the ecological footprint of life is the habitat of time and space, and its surrounding ecological footprint is less than the surrounding space-time environment, affecting the environment Space-time for the background. [5] This essentially distinguishes between habitat and environment. Habitat, can be compared to biological "address", the environment is around the biological "address" of the surrounding world, that is, Habitat is the living place of living creatures, the environment is biological activity place. Compared with the social environment, the 
natural factors of habitats are more significant. They follow the laws of nature and have significant hyper-cycle characteristics. Habitat germination, development and promotion and the environment are closely related. In its habitat, survival and growth habitat, the organism carries out all kinds of social activities of producing and living and forming various social relations with other surrounding species. Therefore, the habitat turns from a natural environment with natural properties into a social property Social environment; and those living with individual life can also become a specific habitat, for example, when a tree seed flutters in the wind to the valley, where rooting, germination, growth, and the surrounding ecological factors Interaction and mutual influence make the biological factors and non-biological factors of this environment change and develop, forming a habitat suitable for the species to breed, survive and grow, and also conducive to the survival of other ecological factors in this space.

\subsubsection{Habitat is the natural beauty of the natural structure of germinal gene}

Gene, or cause, or basic cause. Its biological concept supports the basic structure and properties of life. The high-level ecological aesthetics meta-category - the natural beauty of the natural structure of the germinal development and the formation of its performance, can not be separated from the genetic role of habitat. The United States is the common aspirations and systematic nature of all human aesthetics. They are the essential requirements of the ecological aesthetic civilization, the fundamental of all aesthetic cultures, and the aims of all aesthetic disciplines. If we leave the environment of ecological civilization and the habitat of ecological aesthetic civilization, the civilized circle of the United States and China can not germinate, the nature structure of the natural beauty field cannot be formed and the ecological aesthetics can not achieve its cog- It is impossible to achieve the ultimate ideal of natural beauty[12].

\section{Conclusions}

Habitat is the origin and basic category of ecological aesthetics. The "Tao" of nature in life elevates the concept of habitat to a philosophical level. From the perspective of genesis, ecological aesthetics affirms the position of system life from habitat. The formation of the universe spinning spinosyns, in the habitat gave birth to the system of life, when the natural beauty of the original state of life has become a living organism with the world's senses, aesthetic activities have also arisen.

The habitat formed by the spin of the universe is not only the basic condition of systematic birth, but also provides the possibility for the generation of human aesthetic activities, which lays the foundation for the emergence and expansion of ecological aesthetic field. From the beginning of its formation, the ecological aesthetics developed into a fractal and transitional form and advanced to a higher form, demonstrating the germinal laws of the beauty field. Ecological aesthetic civilization is a habitat of ecological aesthetics. Systematic life unfolds in the habitat, obtains the ecological freedom again in the habitat, finally realizes the high unification of the freedom and the beauty, and then moves towards the ultimate ideal of ecological aesthetics - natural beauty.

Habitat, and the dynamic development of ecological aesthetics to form a dynamic relationship between the formation of ecological aesthetics, fractal, Gestalt shape with basic significance. Without habitat, there is no life, no ecology, no aesthetic ecology, nor the germination and development of ecological aesthetic system. Without the habitat, ecological aesthetics also loses the foundation of systematic germination and its motive force and condition for development and promotion. Habitat generation, development, the achievements of the United States, the formation, development, enhance the aesthetic ecology, the structure of aesthetic ecology to Gestalt, that is, the United States Health, and thus the achievement of ecological aesthetics.

\section{References}

[1] Zeng Fan-ren. Ecological Ontology Aesthetics Discussion [M]. Changchun: Jilin People's Publishing House, 2009: 11 
[2] Feng Xiaolu. Aesthetic foundation in human life [J]. Academic Monthly, 2000: 5-7

[3] Feng Xiaolun. The logical starting point of human aesthetic activities is life [J]. Guizhou Social Sciences, 2010: 22-26

[4] Yuan Dingsheng. Natural aesthetics [M]. Beijing: Science Press, 2017: 142; 16-17; 1; 150

[5] Yuan Dingsheng. The Aesthetics of the Whole Life [M]. Beijing: The Commercial Press, 2013: 4; $26-27$

[6] Yuan Dingsheng. Philosophy of Ecological Art [M]. Beijing: Commercial Press 2007: 217

[7] Yuan Dingsheng. On the United States is the whole birth [J]. Journal of Guangxi Normal University, 2012 (5): 67-73

[8] Yuan Dingsheng. Aesthetic Ecology [M]. Beijing: Encyclopedia of China Publishing House, 2002: 68

[9] Yuan Dingsheng aesthetic field theory [M]. Nanning: Guangxi Education Press, 1995: 9

[10] Yuan Dingsheng and Yuan Dingsheng - Ecological Aesthetics [M]. Beijing: Wirefitting Bookstore, 2013: 37-38

[11] Ilkka Hanski. The Shrinking World - The Ecological Consequences of Habitat Loss [M]. Beijing: Higher Education Press, 2006: Foreword

[12] Yuan Dingsheng. Ecological Aesthetic Field - the Category of Ecological Aesthetics [J]. Poyang Lake Journal, 2009: 61-69

[13] Yuan Dingsheng aesthetic aesthetic direction [M]. Guilin: Guangxi Normal University Press, 2012: 7 